\title{
Intuitive Conceptions of Dead Agents' Minds: The Natural Foundations of Afterlife Beliefs as Phenomenological Boundary*
}

\author{
JESSE M. BERING**
}

\begin{abstract}
Little is known about how the minds of dead agents are represented. In the current experiment, individuals with different types of explicit afterlife beliefs were asked in an implicit interview task whether various mental state types, as well as pure biological imperatives, continue after death. The results suggest that, regardless of one's explicit reports about personal consciousness after death, those who believe in some form of life after death (and, to a certain extent, even those who do not) implicitly represent dead agents' minds in the same way: psychobiological and perceptual states cease while emotional, desire, and epistemic states continue. The findings are interpreted according to simulation constraints - because it is epistemologically impossible to know what it is like to be dead, individuals will be most likely to attribute to dead agents those types of mental states that they cannot imagine being without. Such a model argues that it is natural to believe in life after death and social transmission serves principally to conceptually enrich (or degrade) intuitive conceptions of the afterlife.
\end{abstract}

\section{KEYWORDS}

Evolution, religion, afterlife, simulation theory, mental, representation.

Before discussing the underlying cognitive mechanisms involved in afterlife beliefs, it is important to first understand the broader theoretical context within which the current topic of investigation lies. Over the past decade

* Support for this project was partially provided by a dissertation year grant awarded to the author by the Charles E. Schmidt College of Science at Florida Atlantic University.

**Department of Psychology, University of Arkansas, Fayetteville, AR 72701. E-mail: jbering@uark.edu. 
or so, there has been a noticeable expansion of interest in the cognitive underpinnings of religious thought (for reviews, see Andresen 2000; Atran 2002; Barrett 2000; Boyer 2001; Hinde 1999; Malley 1996). Much as investigations of language and culture profited from the hybridization of academia — specifically of biology, psychology, and linguistics - developments in this area are due mainly to the incursion of interdisciplinary cognitive science into domains traditionally occupied by social and cultural anthropologists. With cultural relativism falling to the wayside (or, at least, playing second fiddle) in order to make room for discovery of underlying universals in cognitive processing, there began to emerge convincing evidence that specific systems of representation were behind various aspects of religion (Boyer 1994; Guthrie 1993; McCauley \& Lawson 1990) and, to a lesser extent, spirituality (Whitehouse 1995, 2001). Interestingly, it was anthropologists, dismayed by what they saw as an undue emphasis on the differences between belief systems, who set the precedent for these important changes. The earlier work in this area, then, was largely theoretical statements and logical argumentation for shifting comparative cross-cultural analyses of religious systems away from superficial differences and toward the study of shared cognitive mechanisms and, ultimately, evolutionary origins.

Only very recently has a small group of empirical psychologists and cognitive anthropologists recognized the importance of these developments and begun to contribute experimentally derived data to the cause (Barrett \& Keil 1996; Barrett \& Nyhof 2001; Barrett, Richert \& Driesenga 2001; Boyer \& Ramble 2001; Evans 2001; Giménez, Guerrero \& Harris unpublished manuscript; Rosengren, Johnson \& Harris 2000; Woolley 2001; Woolley \& Phelps 2001). For instance, Barrett (1998a; Barrett \& Keil 1996; for theoretical review see Barrett 1998b) has shown in several notable experiments that, although individuals may profess "theologically correct" beliefs about various deities (e.g., that God is omnipresent), when forced to actually reason about and use these agent concepts in real time, such believers overwhelmingly treat these superhuman agents as if they were regular men and women on the street. Thus, after reading a narrative in which a little boy clung to a tree branch after falling into the river and prayed to God for help at the exact same moment that God was answering another person's prayers, when recalling the story the majority of participants 
(nearly all of whom subscribed to conventional Judeo-Christian teachings) reported that God finished answering the first prayer and only afterward saved the little boy.

The pressing question, of course, is if believers really do represent God as temporally unconstrained and omnipresent, why do they answer that he must complete tasks sequentially, as do we "mere mortals"? "Participants quite readily attributed to God properties such as having a limited focus of attention, having fallible perceptual systems, not knowing everything, and having a single location in space and time. In contrast, when these same participants were asked using questionnaires to reflect on what properties they believed God has, they reverted back to the theologically correct, abstract: God is all-knowing, has infallible perception, has no single physical location, has unlimited attention, and so forth" (Barrett 1998b, p. 329). Similar data have been reported for religious individuals in India (Barrett 1998a).

Such findings suggest a possible dichotomy between the implicit use of, and the explicit description of, religious concepts, wherein once explicit concepts are acquired through cultural channels they must map onto default inferential networks geared for use in everyday situational demands, such as explaining and predicting others' behavior. Thus, God is endowed with no more superhuman powers than you or I (save the ability to engage in mental-physical causality; see Bering 2002a; Woolley 2001) in the narrative tasks because he is implicitly represented as an intentional agent in possession of a standard catalogue of mental abilities, which are characterized by their own constraints (e.g., the inability to attend to two speakers at the same time).

\section{Counterintuition and Constraint on Religious Thought: Inferences and Generativity of Implicit Knowledge}

The origins of these constraints are of considerable interest in themselves. Cognitive developmentalists have long speculated on the role of innate knowledge in human ontogeny. Starting with theoretical linguist Noam Chomsky's (1965) discussions of an inborn "Language Acquisition Device" that steers infants and toddlers toward effortless mastery of their native tongue and subscription to basic grammatical rules, strictly behavioristic theories of learning have been seriously undercut by a fusillade of exper- 
imental findings showing various forms of implicit knowledge in young children (see Carey \& Spelke 1994; Pinker 1997; Spelke 1994; Sperber 1994). Among the proposed "folk systems" of innate, organized knowledge structures are those of domains dealing with biological (e.g., taxonomy, essentialism), physical (e.g., gravity, mass), and psychological (e.g., intentions, desires) phenomena. Although the 9-month-olds' knowledge of physics, for example, is still a work in progress, evidence suggests that even at this early stage, infants have an understanding that two bounded objects cannot coexist in space and time (Baillargeon 1993; Spelke 1991). Likewise, by their first birthdays, infants seem to have an intuitive understanding that behavior is generated through unobservable causes, such as goals and intentions (Baron-Cohen 1995; Gergely, Nadasdy, Csibra \& Biro 1995).

Most developmentalists envision a process in which such supportive, implicit knowledge is conceptually enriched and elaborated with experience ("adding flesh to bones") to give weight to the mature folk systems seen in older children and adults (Karmiloff-Smith 1992). Importantly, these experiences will be largely the same, because the world is governed by certain ontological regularities that are seldom, if ever, actually violated. Thus the mature, adult endpoint of conceptual change will reflect culturally recurrent trends, regardless of superficial differences in cultural forms (Atran 1989; Sperber, Premack \& Premack 1995).

Wherein, then, lies religion, which is saturated with metaphysical assumptions, concepts that egregiously violate such ontological regularities, such as an agent that can be everywhere at the same time, or a tree that can hear? It is precisely these attention-grabbing, intrinsic violations, according to anthropologist Pascal Boyer (1994, 1996, 2001), which enables - indeed, almost demands - the acquisition of specific religious concepts, and can account for culturally recurring themes in diverse belief systems (e.g., invisible intentional agents, animistic attributions). Indeed, recent evidence shows that recall memory for counterintuitive concepts within the handling limits of the constraint systems is significantly higher than for mundane concepts that possess no ontological violations (Barrett \& Nyhof 2001; Boyer \& Ramble 2001). For instance, Barrett and Nyhof (2001) had participants read Native American folktales containing both natural and supernatural items. When asked later to retell these same stories, participants were more likely ( $92 \%$ recall) to remember minimally counterintu- 
itive items than they were intuitive ones (71\% recall). Importantly, "[A] supernatural concept also activates the intuitive expectations that are not violated, among those associated with the relevant ontological category. This remains generally tacit and need not be acquired via social transmission" (Boyer 2000, p. 197; italics in original). Sperber (1994) reasons that it is in such ways that religious concepts can be conceived as "parasitizing" natural domains and their inference systems and religion comes to resemble an "epidemiology of representations."

\section{"Ghost" Concepts in the Boyerian Tradition}

To focus on one example of particular relevance to the current paper, the concept of ghost or spirit would owe its preponderance among the vast majority of societies, according to this rationale, to its counterintuitive properties: Among other neat tricks, the souls of the deceased are invisible and can walk through walls. And because it deals with the ontological category PERSON, individuals (the living ones, that is) are primed by default to respond to the supernatural concept ghost as if these entities were intentional agents of the human variety. That is, believers will ascribe mental states to them, and assume that they are interested in such things as engaging social chatter and the regulation of (im)moral behavior, just as the living are.

Of course, this is a highly watered-down version of Boyer's original model of religious concept acquisition and use, but the important point here is that the model holds unequivocally that ghosts should be no different than living people when it comes to basic psychological functioning, at least as they are represented in human minds. All else being equal, afterlife believers should be no more likely to state, for instance, that their deceased loved ones have the capacity to be perceptually active than they are to reason that they still possess desires and beliefs. Boyer (2001, pp. 73-74; italics in original) reasons:

The concept [ghost] is that of a person who has counterintuitive physical properties. Unlike other persons, ghosts can go through solid objects like walls. But notice that apart from this ability, ghosts follow very strictly the ordinary intuitive concept of PERSON. Imagine a ghost suddenly materializes in your home as you are having dinner. Startled by this sudden appearance, you drop your spoon in your plate of soup. In a 
situation like that, your mind creates a whole lot of assumptions of which you are not necessarily conscious. For instance, you assume that the ghost saw you were having dinner, so she now knows that you are eating. Also, the ghost probably heard the sound of your spoon landing in the soup and can now remember that you dropped it. You assume that the ghost knows you are here, since she can see you... In other words, you assume that this ghost has a mind.

Perhaps, however, it is Boyer who assumes the ghost has a mind, or at least a mind indistinguishable from those of living people. Although he glosses over the above description of the ghost's mental activities as "banal" and quite obviously in line with how individuals would represent the mental functioning, epistemic or otherwise, of dead agents, Boyer asks us to accept his account on faith alone. Others offer similar claims: "[Ghosts] can suffer just as if they had bodies" (Hinde 1999, p. 71). In fact, though the anecdotal database ostensibly leaves little to the imagination, there have been absolutely no controlled experimental studies done to assess how individuals actually represent the minds of those who have died. Atran and Norenzayan (in review) note one problem with the above model: because they are invisible, causal intuitions dealing with spirits must be realized in absentia of an actual agent; even the expectation that there exists material agency behind actions can never be realized in principle, since it is precisely the agent's supposed counterintuitive properties [invisible + PERSON] which provides it with a conceptual identity.

Indeed, the question remains why individuals the world over represent the minds of those who have died to be active at all, since tacit biological knowledge of death and agency might just as easily have resulted in the complete absence of the concepts ghost, spirit, or afterlife. C. Barrett (1999), for example, has shown that even toddlers seem to have an intuitive grasp of death, reasoning that animals killed by predators will cease to be able to act, and will not be alive again. Bering and Bjorklund (2002) found nearly identical results with a sample of preschoolers and kindergartners using anthropomorphized predator-prey characters. While cultural epidemiologists might presuppose that it is precisely this intuitive knowledge of death that renders the child susceptible to afterlife concepts (e.g., the idea of resurrection violates the implicit notion that death is irreversible), this does not solve the very real problem of why specific 
counterintuitive concept categories such as those dealing with afterlife beliefs would spontaneously happen to appear in nearly all societies to begin with.

The postulate that ghost is a cultural invention may be misguided in that it overlooks the possibility that not only the spontaneous inference system triggered by it, but also the very concept itself, has natural foundations in the human mind. In other words, is it possible that the general idea of an afterlife is not so much implanted in people's heads by way of "exposure" to counterintuitive tales, as it is already present, already firmly entrenched in representational structures endemic to human cognition, and only then conceptually enriched through cultural channels? Can we not scarcely help but believe in some form of psychological continuity of the dead? To answer these questions, we must look at both the evolutionary and developmental emergence of those cognitive systems necessarily involved in the formation and maintenance of afterlife beliefs, and how these systems might be instantiated upon actual encounters with death and upon reasoning about the mental status of the deceased.

\section{Second-order Representation: Evolutionary Emergence and Thanatological Relevance}

Several evolutionary theorists have argued that the ability to predict and explain behavior by mentally representing the unobservable causal states presumably spurring an agent to action is a definitively human cognitive specialization, at least to the degree it is displayed by Homo sapiens (Bering \& Povinelli, in press; Povinelli, Bering \& Giambrone 2000; Bjorklund \& Pellegrini 2002; Heyes 1998; Tomasello 1999; Tomasello \& Call 1997; Suddendorf \& Whiten 2001). While generally referred to as a "theory of mind," this ability, at its most basic level, is most parsimoniously labeled second-order representation because it implies the mental representation of other mental representations (e.g., "I know that you remember what happened last night."). This capacity is important in the present context because without second-order representation to give a ghost its thoughts, a corpse is but a corpse is but a corpse. Spirits and ghosts (and gods, for that matter) are essentially disembodied minds; the question I am interested in here is in relation to the fundamental complexion of these minds as they are represented in active human brains. 
Although initial comparative investigations tended to suggest that other primate species, particularly chimpanzees (Pan troglodytes), possess homologous mechanisms of social cognition (e.g., Gómez 1990; Gómez \& Teixidor 1992; Povinelli, Nelson \& Boysen 1990, 1992; Premack \& Woodruff 1978), the majority of findings from more recent, carefully controlled laboratory studies suggest quite the opposite: That chimpanzees, no matter how much their social behavior resembles our own, are unable to attend to the underlying causes of these behaviors (e.g., Call \& Tomasello 1994, 1999; Povinelli, Bierschwale \& C̆ech 1999; Povinelli \& Eddy 1996; Povinelli \& O’Neill 2000; Reaux, Theall \& Povinelli, 1999; Tomasello, Call \& Gluckman 1997; for reviews, see Povinelli 2000; Tomasello \& Call 1997). Few, however, would argue that chimpanzees do not reason at some level about intentions and desires, in that they perhaps view others merely as goal-directed, animate agents (Tomasello 1999; Tomasello \& Call 1997). But in terms of explicit representation of mental states, there has only been a single controlled series of studies reporting convincing evidence that apes are anything other than "mindblind" (Hare, Call, Agnetta \& Tomasello 2000; Hare, Call \& Tomasello 2001) and even these findings have recently been called into question (Karin-D’Arcy \& Povinelli, in review).

Together, the implications of these data are significant, as they suggest that although the historical antecedents of human behavior are ancient indeed and can be traced back at least to the time our species shared a common ancestor with chimpanzees ( $\sim 6-7$ mya), the evolution of secondorder representational abilities enabled humans to "redescribe" this core behavioral assemblage by reasoning about the variegated suite of mental states structurally supporting it (see Povinelli, Bering \& Giambrone 2000). That is, individuals were able to "read into behavior" in a way that organisms unaware of other minds, and thus held captive to whatever static information their perceptual devices supplied them with, simply could not. Some scholars have speculated that the sophistication of this emergent intentionality system may have precipitated declaratively based communication (see Kita, in press) and, eventually, cultural innovation (Bering 2002b; Tomasello, Kruger \& Ratner 1993; Tomasello 1996, 1999) - as both hinge on the capacity to intentionally transfer knowledge to other minds. In any event, whatever the evolutionary primacy of these things, the adaptiveness of the system can hardly be debated. It is the 
difference between following you in the forest because you started walking that way and following you in the forest because I think you know where Fonah stashed the meat. And - without trying to sound as if natural selection is a teleological enterprise - interestingly, with the appearance of the system might have come some "unanticipated" evolutionary byproducts, including both the capacity and a natural proclivity to believe that mental states continue after death, something I shall address shortly.

Admittedly, much in the way of primate social cognition remains to be resolved experimentally, but insofar as the current empirical database reflects a true state of affairs, it can at least partially account for how chimpanzees and other primate species can respond in relatively unusual manners to the sight of dead conspecifics, as they are anecdotally reported to do (Goodall 1990; Harper 1996; Matsuzawa 1997; Teleki 1973; de Waal 1996). The cessation of agency, as well as the severing of affiliative relations between the dead and the living, may govern death-exploratory behavior and, in some cases, even grieving (Zeller 1991). Humans, in contrast, while also displaying aversion-attraction behaviors toward dead bodies and intense grief upon the loss of significant others, in addition to these elements conventionally practice such things as ritualistic disposal of the body and ancestral obeisance (Reynolds \& Taylor 1995); Homo sapiens seems compulsively reserved to assuaging what are perceived to be the decedents' ongoing emotive states (for a more detailed treatment of this comparative issue, see Bering 2001a). As recently as 1998, 82\% of Americans reported that they believed in life after death (Greeley \& Hout 1999).

\section{Explaining, Predicting, and Modeling the Actions of Spirit Minds (Or, how the dead go on)}

Although there is some convincing evidence that infants and young children have a low-level, implicit understanding of mental states, the bulk of the data in this area overwhelmingly show that the sort of representational abilities discussed previously come online unequivocally at about four or five years of age (for reviews, see Flavell 1999; Wellman, Cross \& Watson 2001). It is at this age that children begin to pass the standard verbal false-belief and appearance-reality tasks, what have come to be regarded as litmus tests for an individual's capacity to understand that 
internal representations of the world are not necessarily veridical with an external reality. That there is a high degree of developmental canalization of this intentionality system has been supported by cross-cultural evidence of age parallel emergence in children of small-scale societies (Avis \& Harris 1991).

Of course, the fact that the maturational process occurs relatively unperturbed in all healthy children tells us little about the precise mechanisms of development, which need not concern us here except to say that the operations by which these representational skills are invoked in individual minds may have some important bearing on intuitive afterlife concepts. Most accounts of the actual mechanisms involved are meant to explain the developmental sequence of metarepresentational competencies and therefore incorporate early ontogenetic changes to the initial system over time. Yet each has as an endpoint a mature conception of the system with a specific modus operandi applying also to adult social cognition, and these may have inherent implications for a model of the natural foundations of afterlife beliefs.

While not necessarily representing the dominant view of metarepresentational emergence in ontogeny, simulation theorists (Goldman 1993; Harris 1991, 1992) hold that children become increasingly adept at running analogical models for other minds by using their own subjective experiences as the primary comparative source (e.g., "What would I think if I were in his shoes?"). Thus, according to simulationist accounts, false belief tasks can be solved only insofar as a child is able to override their own knowledge of the location of the hidden object and imagine where someone who did not witness the hiding event would think it is. Simulation theory makes specific predictions about how people reason about the minds of dead agents. According to Harris (1991, p. 292), "A simulation of the other person can only be achieved if the child imagines both [a] discrepant reality, and the divergent stance that the other person takes toward it." The afterlife poses a special problem here quite simply because it is epistemologically impossible to know what it is like to be dead, and thus the normal default background of personal experience with which an individual routinely uses to model others' experiences will not be a precise match but rather an imaginary point of comparison (e.g., non-REM sleep or biblical accounts). And because the absence of certain types of mental 
states have been subjectively experienced (e.g., satiation of thirst, hunger; absence of seeing, hearing), it should be easier for individuals to represent the discontinuity of these functions than for other types of mental states, the complete absence of which has never been consciously experienced (e.g., not thinking; not knowing) or has only been minimally experienced (e.g., not wanting; not loving). That is, because afterlife believers know what it feels like to be without certain types of mental states (hereafter referred to as "EIA states" - easy-to-imagine-the-absence-of-states) more readily than others (hereafter referred to as "DIA states" — difficult-to-imagine-the-absenceof-states), they should treat mental state types differently when reasoning about the minds of dead agents, being more likely to say that ghosts and spirits still possess those psychological properties that they themselves cannot imagine being without.

A very general a priori ordering of mental state types holds that both psychobiological and perceptual states should be classified as EIA states in that the absence of both are routinely consciously experienced, whereas desire, emotional, and, especially, epistemic states should be classified as DIA states since their complete absence is rarely encountered in consciousness (and, in the case of epistemic activity, never experienced in consciousness). Although we frequently fail to remember certain things, or to know certain things, for example, we are never entirely deficient of memory during consciousness, nor is our knowledge store ever wiped completely clean. The same can be said for mental states comprising our experiences of emotions and desires. For example, although we may fail to love somebody or something in particular, we are never consciously without the capacity for that emotion in general: it can always find a target in someone or something (e.g., one's mother or fiancé or pet dog). Likewise, a particular desire can be met, but never are we entirely without goals. (Of course, there may be ranges of absolute absence of emotion and desire states.) In contrast, with psychobiological and perceptual states, we are often without them in their entirety, e.g., when we are not hungry, we have no hunger toward anything; when we cannot see, we cannot see anything, and so on.

In the current study, undergraduate students were asked to participate in a structured interview meant to flesh out how they represented the minds of those who have died. Because specific afterlife beliefs do not necessarily 
inhere to an individual's religious affiliation (e.g., one may be a secular Catholic and an atheist), participants were asked to classify themselves according to general "afterlife believer-type" categories (after Thalbourne 1996a, 1996b) in order to determine how explicit beliefs work with an implicit inferential system. For instance, someone who believes in bodily reincarnation may reason that the dead will need to eat food and drink water again, something which, according to nativistic theories of death knowledge (e.g., Bering \& Bjorklund 2002; C. Barrett 1999; Slaughter, Jaakola \& Carey 1999), might seem "unnatural." Unlike previous studies which have focused on motivational reasons for believing in an afterlife ("why?"), the current study was different in that it was the first to investigate the mechanisms for believing in an afterlife ("how?"), and possible implicit representations of dead agents' minds.

In order for the simulationist model for the "intuitiveness" of belief in life after death to be borne out, several hypotheses must be supported. First, if indeed DIA states are more resistant to discontinuity reasoning because this requires that explicit biological knowledge must deliberately "turn off" the default simulation system, then all individuals, no matter their professed beliefs on the fate of personal consciousness after death, should be more likely to say that DIA states continue after death than they are EIA states, where biological knowledge can effectively co-opt the default system. That is, although an extinctivist (someone who believes the self is wholly extinguished at death) will be more likely to say that dead people no longer have the capacity to have mental states than will an immortalist (one who believes that the self survives death intact, shedding only the physical body), both types of believers should be less likely to state that DIA states cease at death than EIA states. In addition, it could be argued on the basis of the predictions made by the simulation model that discontinuity response latencies should be, in general, longer for DIA than for EIA states, since the former would require that reflexive simulation attempts be overwritten by explicit biological theorizing to arrive at such responses, reasoning about death in full scientific fashion, while the latter employs default simulations. ${ }^{1}$

\footnotetext{
${ }^{1}$ On a related note, Flavell, Green, Flavell, and Lin (1998; see also Flavell \& O'Donnell 1999) found that 5-year-olds, but not 8-year-olds, attribute decision-making abilities and self-awareness to a person "sound asleep and not dreaming." This presumably reflects
} 
Alternatively, if indeed afterlife beliefs are principally culturally acquired variants of particular religious themes, representing mainly a product of exposure to specific ideas about the fate of personal consciousness after death, and having little to nothing to do with inborn simulation constraints, then all question types should be treated the same within afterlife believer-type categories. According to the null hypothesis, there should be no differentiation made along DIA/EIA lines. That is, an extinctivist should be just as likely to say that one type of psychological state (e.g., desire) discontinues after death as the next (e.g., perceptual). Likewise, an immortalist should envision the "soul" (i.e., mind) as leaving the body at death, but otherwise remaining intact after death, possessing the same ensemble of basic mental capacities prior to death. This predictive model seems closely aligned with Boyer's depiction of ghosts' minds as presented earlier: simply, a standard human mind with a full suite of psychological state types.

\section{Method}

\section{Participants}

Participants were 84 undergraduate students recruited from the psychology subject pool at Florida Atlantic University and who were enrolled in an introductory psychology course at the time of testing. The university is located in a suburban metropolitan area of South Florida and its student population is represented by a diversity of ethnic, cultural, and socioeconomic backgrounds. The average age of the participants was 20.1 years (range $=17.6-36.3$ years), with 27 males and 57 females who took part in the experiment.

the fact that only with an increase in explicit biological knowledge can scientifically informed decisions about unknowable mental phenomena be made. For instance, because the absence of action does not necessarily imply the absence of intentional states (e.g., daydreaming), any theory discounting cognitive activity in dead bodies must be recruited from biological knowledge which tells us (1) that the dead cannot be made alive again (implicit knowledge); and (2) that the brain, which is responsible for mental states, stops working at death (explicit knowledge). 


\section{Materials and Procedure, Vignette and Afterlife Interview}

Two page-length vignettes that were category-matched and counterbalanced across participants served as the primary materials (see Appendix 1). The vignettes (Script A and Script B) involved short stories about a male or female protagonist who met an unexpected death at the end of the story, interrupting the character's ruminative flow established in the text prior to the death.

Participants were tested individually in a private room adjacent to the investigator's laboratory office. Prior to the experimental session, participants read and signed a consent form that described the study as an "interview and brief questionnaire meant to assess people's afterlife beliefs." Each participant was randomly assigned to either Script A or Script B. Participants were left alone in the room and were asked to read the story two times. Prior to reading, they were told that they would be tested on the material after they finished the story. When they had finished, the experimenter returned to the room and informed the participants that they would be asked a series of questions concerning the dead protagonist from the story, and that they would be allowed to keep the vignette before them in case they would like to reread something in the text that was related to the interview questions. They were also instructed that, although the questions may sound unusual, to answer them seriously; also, due to the nature of the questions, participants were told that there were no wrong or right answers and that the experimenter was only interested in their opinions. Participants were also asked to avoid overly general religious, philosophical, or otherwise abstract and lengthy responses and to provide instead a specific answer to each question as it was asked, providing an initial "yes" or "no" response to the question and then a clear justification for this response upon follow-up questioning (e.g., "And why do you say no?").

Each interview contained questions dealing with 5 mental state categories: (1) PSYCHOBIOLOGICAL (e.g., "Is he still hungry?"); (2) PERCEPTUAL (e.g., "Can he see the paramedics trying to resuscitate him?"); (3) EPISTEMIC (e.g., "Is he thinking about his wife?”); (4) EMOTIONAL (e.g., "Is he still angry at his wife?") and; (5) DESIRE (e.g., "Does he want to be alive?"). (See Appendix 1 for a complete list of questions.) Presentation of questions was counterbalanced such that questions from the same 
category were never asked consecutively. To assure that participants understood that the questions applied after the character's death and not before, the experimenter prefaced each question with, "Now that he's (she's) dead..." Each mental state category contained four specific states with properties adhering to its category type. These representative mental states for each category encompassed a wide range of basic states associated with that category (e.g., the PERGEPTUAL category included questions about seeing, hearing, tasting, and smelling), and all participants were asked questions about this same set of basic mental state functions, regardless of their assigned script. In addition to the mental state categories, each interview contained questions related to pure death-related knowledge of biological constructs that did not require participants to reason about the psychological functioning of the dead story character (e.g., "Will he ever need to drink water again?"). Again, all participants, regardless of which script they were assigned, were asked questions dealing with the same set of biological constructs. With the inclusion of this BIOLOGICAL category, each interview session contained a total of 24 primary questions.

\section{Materials and Procedure — Belief in Afterlife (BA) Scale and Death Anxiety Scale $(A \mathcal{N} X[d])$}

Immediately following the interview session, participants were asked to complete a 35-item questionnaire and to provide Likert-type responses (15) to a host of death-related questions (see Appendix 2). Embedded in the questionnaire were two separate scales, the Belief in Afterlife (BA) Scale (20 items) and the Death Anxiety Scale (ANX $[\mathrm{d}])^{2}$ (15 items), both of which have been used separately in previous research (Berman \& Hays 1973; Littlefield \& Fleming 1984; Lonetto \& Templer 1986; Osarchuk \& Tatz 1973; Schoenrade 1987; Smith, Range \& Ulmer 1992; Templer 1970; Templer \& Ruff 1971; White \& Handal 1991). The Belief in Afterlife (BA) Scale was created by Osarchuk and Tatz (1973) and is intended to measure "the degree to which an individual believes that life continues, in some form, after the physical death of the body. It is not, however,

${ }^{2}$ The standard acronym for this scale as it was originally used by Templer (1970) is DAS. I have changed it here to $\operatorname{ANX}(d)$ in order not to confuse the reader with a similar acronym — DIA (difficult-to-imagine-the-absence-of) — that is employed throughout the text. 
intended to measure belief in any particular form of afterlife; the wording of items on the test could be equally agreed with by someone who believes in reincarnation as one with a more, for example, Orthodox Christian view of the hereafter" (Hill \& Hood 1999, p. 113). Reliability analyses on the BA scale by Casebolt (1992) yielded a Cronbach's alpha of .89, and various comparisons with alternative measures of afterlife belief have consistently found high validity for the scale (Berman \& Hays 1973; Kurlychek 1976; Littlefield \& Fleming 1984). This scale provided an independent measure of how undifferentiated belief in life after death was related to an individual's characterization of a dead agent's mental and biological functioning. Thirteen of the twenty items in the BA scale were reverse-scored. After correcting for such items, participants' scores were obtained by summing those responses that reject belief in the afterlife, such that a higher score reflected greater belief that life continues, in some form, after death.

The Death Anxiety Scale (ANX[d]) was first used by Templer (1970) and measures an individual's attitude toward the subject of death. The $\mathrm{ANX}(\mathrm{d})$ incorporates a number of components related to death anxiety, including concern about pain and stress that may accompany illness, intellectual and emotional reactions toward death, concern about growing old, and concern about the passage of time (Lonetto \& Templer 1986). Hill and Hood (1999) report that the $\operatorname{ANX}(d)$ scale yielded a test-retest reliability correlation coefficient of .83 , and construct validity has been adequately established (Hill \& Hood 1999; Templer 1970). Six of the 15 items on the $\operatorname{ANX}(d)$ were reverse-scored such that, after correcting for these items, adding together the total score yielded a composite that reflected a person's overall attitude toward death. Higher scores indicated greater anxiety toward death-related topics. This scale provided an independent measure of how an individual's emotional reactivity toward death was related to the characterization of a dead agent's mind and biological status.

In addition to completing the questionnaire, after reading descriptions of 6 different afterlife believer-type categories (Thalbourne 1996a, 1996b; see Appendix 3), participants classified themselves as either extinctivists (cessation of personal consciousness at death), agnostics (uncertain as to what becomes of personal consciousness at death), immortalists (personal consciousness survives the death of the body and exists forever), reincarnationists 
(personal consciousness is reincarnated into a new body after death), eclectics (combination of immortalist and reincarnationist classifications), or others (personal consciousness survives the death of the body but uncertain what happens after this). To reduce potential response bias on the interview and questionnaire, data concerning participants' specific afterlife believer classification were collected at the very end of the experimental session. In contrast to the more general BA scale, afterlife believer-type classifications were done in order to determine how explicit, rather than general, beliefs about life after death intersected with attributions made toward a dead agent, and how such beliefs might exploit or countermand natural inferential processes.

\section{Coding of Interview Sessions}

Interview sessions were recorded on audiotape and later transcribed. The experimenter also coded the participants' responses online as backup data in the case of audio recorder or audiotape malfunction (which did not occur), and for two participants who preferred not to have their interviews recorded. With the exception of these two cases, transcriptions of the interview sessions served as the primary data source.

Answers to interview questions were scored according to operational criteria establishing likely continuity reasoning (the specific biological imperative or mental state is envisioned to function despite the character's death) or discontinuity reasoning (the specific biological imperative or mental state is envisioned to have ceased functioning as a result of the character's death). Any responses that could not be classified as reflecting either continuity or discontinuity reasoning were considered unscoreable.

The full criteria used to classify a response as denoting continuity reasoning or discontinuity reasoning are provided in Appendix 4, along with actual examples of participants' responses. In most cases, initial affirmative answers to the questions were unequivocal evidence of continuity reasoning. For instance, if when asked, "Now that Richard is dead, is he still angry at his wife Martha?", the participant responded "yes," and his or her answer to the follow-up question (e.g., "How come?") matched this affirmative response (e.g., "Because he suspected she was having an affair."), then a continuity score on this EMOTIONAL item was coded. For BIOLOGICAL items only, initial negative answers were usually evidence 
of discontinuity reasoning. For example, if when asked whether Tracey would ever need to go to the bathroom again, the participant answered "no," and his or her answer to the follow-up question (e.g., "Why not?") matched this initial negative response (e.g., "Because when you're dead you don't have to do that."), then a discontinuity score was coded for this BIOLOGICAL item. However, for all other categories (i.e., all mental state categories), initial negative answers required a careful assessment of replies to follow-up questioning because stating "no" in response to the target questions did not offer sufficient evidence of discontinuity reasoning. For example, the participant may have said that Richard did not know that he was dead, but may have based this answer on Richard's presumed knowledge (e.g., "He's confused," "He thinks he's still alive," etc.) rather than on the permanent cessation of Richard's ability to know.

In those cases where a participant displayed uncertainty by changing his or her initial "yes" or "no" response between the target question and the follow-up questions for that item, the second response was coded. However, in the event that a participant's answer to a follow-up question did not match his or her "yes" or "no" response, an unscoreable classification was recorded for that particular item. Also, because coding was based on the individual's reasoning about specific biological imperatives or mental states, it was therefore possible to present answers that reflected general afterlife beliefs while maintaining discontinuity reasoning for the item in question (e.g., "Ghosts don't need to eat food"). In other words, individual interview questions were not an attempt to discover whether participants believed in life after death; they were attempts to discover whether participants believed in the continuity or discontinuity of each particular mental state function or biological imperative after death.

The author and a second person naïve to the purposes of the study served as independent coders. Initial interrater reliability on a random sample of twenty percent of the database was $92 \%$ and all disagreements were subsequently resolved by reviewing the episodes in question.

\section{Primary Statistical Analyses}

To assess whether fear of death, or death-related anxiety, could account for any differences in afterlife believer-type classifications, a one-way analysis of variance using the $\mathrm{ANX}(\mathrm{d})$ factor as the dependent variable was conducted. 
Similarly, to help assess questionnaire validity, the relationship between general afterlife beliefs (BA) and the more specific afterlife believer-type classifications was tested using a one-way analysis of variance with the BA factor as the dependent variable; to prove valid, individuals who labeled themselves as immortalists, eclectics, reincarnationists, and other believers should generally score higher on the BA scale than agnostics and extinctivists. A series of correlations was also performed between the BA and $\operatorname{ANX}(\mathrm{d})$ factors, and between each of these variables and the percentage of discontinuity responses for each question type (i.e., biological, psychobiological, perceptual, emotional, desire, epistemic); in order to control for the high number of comparisons made for these tests, a stringent significance level of $p<.001$ was adopted. To test the competing hypotheses presented earlier that individuals with different explicit notions about life after death will either (a) treat all mental states the same and in accordance with explicit afterlife beliefs, or be just as likely to say that one type of mental state ceases at death as the next (null hypothesis) or; (b) treat mental state types differently, or be statistically more likely to say that EIA states cease at death than DIA states (simulation constraint hypothesis), a 6 (question type: biological vs psychobiological vs perceptual vs emotional vs desire vs epistemic) $\times 6$ (afterlife believer-type: extinctivist vs agnostic vs immortalist vs eclectic vs reincarnationist vs other) mixed factorial analysis of variance with repeated measures on the question type factor was conducted. All significant effects were then assessed with TukeyKramer post-hoc tests $(p<.05)$. Finally, to explore the hypothesis that participants should have greater facility reasoning that EIA states cease at death than DIA states, a subset ( $n=43$ participants) of the data was coded for latency of response on discontinuity answers. ${ }^{3}$

\footnotetext{
${ }^{3}$ Because these predictions were made $a d$ hoc and were not included in the original hypotheses, the verbal responses of the first 39 participants who were interviewed unfortunately could not be coded; these participants were tested using an electronic (tapeless) voice recorder and the original recordings were permanently deleted following their transcriptions. A conversion to a standard audiotape recording device mid-way through the study allowed a permanent record of the verbal responses from the remaining 43 participants, and it was from these recordings that the latency data were derived.
} 


\section{Results}

Of primary interest was the pattern of discontinuity responses (i.e., stating that the mental state or biological imperative in question ceases at death) as a function of afterlife believer-type classification. The analyses of discontinuity responses reported here excluded all unscoreable responses (2.8\% of absolute response percentage), which consisted of all vague or contradictory responses as well as those missing or considered invalid due to experimenter error. Analysis of the absolute percentage of discontinuity responses produced nearly identical results. In addition, there was no significant difference in the number of unscoreable responses between the six categories of believer-types, nor were unscoreable responses more frequent for any particular question type (e.g., epistemic vs psychobiological). Preliminary analyses of discontinuity responses showed no significant effects of gender, script, or question order on participants' answers and so all subsequent tests employing discontinuity measures were collapsed across these variables.

\section{Participant's Self-Classifications of Afterlife Believer-Types}

After reading descriptions of the six afterlife believer-type classifications, $13 \%$ of participants identified themselves as extinctivists $(\mathrm{n}=11), 15 \%$ as agnostics $(\mathrm{n}=13), 26 \%$ as immortalists $(\mathrm{n}=22), 8 \%$ as eclectics $(\mathrm{n}=7)$, $12 \%$ as reincarnationists $(\mathrm{n}=9)$, and $26 \%$ as other believers $(\mathrm{n}=22)$. The pattern of these data is roughly the same as that reported by Thalbourne (1996), who created the scale for use with Australian undergraduate students. There were no age or gender differences in afterlife believer-type self-classifications.

\section{Belief in Afterlife (BA) Scale and Death Anxiety Scale (ANX[d])}

A series of correlations $(p<.001)$ was computed between the BA (Cronbach's alpha $=.82)$ and ANX $(\mathrm{d})($ Cronbach's alpha $=.82)$ factors, and the percentage of discontinuity responses for each question type (i.e., biological, psychobiological, perceptual, emotional, desire, epistemic). Significant negative correlations were found for the BA factor and epistemic $(r=-.57)$, emotional $(r=-.49)$, desire $(r=-.49)$, and perceptual $(r=-.44)$ states, where, the higher an individual scored on the BA scale (i.e., the stronger 
their belief in life after death), the lower their percentage of discontinuity responses for questions dealing with these mental state categories. However, one's score on the BA scale showed no significant relationship to either the questions dealing with biological imperatives $(r=-.26)$ or psychobiological states $(r=-.20)$. Death-related anxiety was not correlated with percentage of discontinuity responses for any of the mental state categories, nor was it correlated with scores from the BA scale.

A two-way analysis of variance including gender and afterlife believertype with the BA factor as the dependent variable revealed a significant main effect for afterlife believer-type $F(5,78)=8.40, p<.001$. Subsequent Tukey-Kramer post-hoc tests $(p<.05)$ showed that extinctivists $(M=2.89)$ scored significantly lower (i.e., were more likely to state that personal consciousness, in some generic form, ceases at death) on the BA scale than immortalists $(M=3.96)$, eclectics $(M=3.89)$, other believers $(M=3.85)$, and reincarnationists $(M=4.24)$, who did not differ from each other. In addition, agnostics $(M=3.00)$ scored statistically lower on this scale than immortalists, other believers, and reincarnationists, but were undifferentiated from eclectics and extinctivists. There were no significant effects for the gender variable.

Another two-way analysis of variance using the same independent variables, this time with the $\operatorname{ANX}(\mathrm{d})$ factor as the dependent variable, revealed no significant main effects for either gender or the afterlife believer-type variables. Death-related anxiety was moderate $(M=3.04)$ across all groups and did not differ as a function of one's explicit conceptions of what happens after death.

\section{EIA and DIA Factor Analysis}

To determine whether the mental state types used in the current study could be clearly distinguished by the a priori EIA (easy-to-imagine-theabsence-of) and DIA (difficult-to-imagine-the-absence-of) criteria predicted by the simulation hypothesis, the six question categories were intercorrelated and subjected to principal axis factor analysis. Two factors clearly emerged after orthogonal (varimax) rotation, one loading on the biological and psychobiological questions (Eigenvalue $=3.40$ ), and the other on the questions dealing with emotional, desire, epistemic, and to a much lesser extent, perceptual states (Eigenvalue $=1.22$ ). With the exception of the 
perceptual category, which was predicted to fall into the EIA category, these factors represented the original EIA and DIA distinctions. However, because the main hypotheses could best be tested using statistical analyses geared toward detecting differences at more precise levels (i.e., specific question types), subsequent tests did not collapse question types into the two principle components generated by the factor analysis. Instead, the categorical mental states and biological imperatives were held independent of one another.

\section{Percentage of Discontinuity Responses by Question Type and Afterlife Believer-Type Classification}

Figure 1 presents the percentage of scoreable discontinuity responses for each question type posed to the participants, separately for each afterlife believer-type classification. As can be seen from Figure 1, the percentage of discontinuity responses per question type within each afterlife believertype category ranged from $64 \%$ to $100 \%$ for extinctivists, $57 \%$ to $100 \%$ for agnostics, $7 \%$ to $94 \%$ for immortalists, $7 \%$ to $96 \%$ for eclectics, $0 \%$ to $91 \%$ for reincarnationists, and from $16 \%$ to $95 \%$ for other believers. The same figure shows percentage of discontinuity responses for each question type across the afterlife believer-types; for biological questions, percentage of discontinuity responses ranged from $83 \%$ to $100 \%$; for psychobiological questions, $89 \%$ to $100 \%$; for perceptual questions, $49 \%$ to $98 \%$; for desire questions, $7 \%$ to $67 \%$; for emotional questions, $0 \%$ to $64 \%$, and; for epistemic questions, $4 \%$ to $65 \%$.

A 6 (question type: biological vs psychobiological vs perceptual vs emotional vs desire vs epistemic) $\times 6$ (afterlife believer-type: extinctivist vs agnostic vs immortalist vs eclectic vs reincarnationist vs other) analysis of variance with percentage of discontinuity responses as the dependent variable and repeated measures on the question type factor, produced significant effects of afterlife believer-type, $F(5,78)=12.35, p<.0001$ (extinctivist $[M=80.9 \%]=$ agnostic $[M=80.2 \%]>$ other $[M=52.7 \%]$ $=$ immortalist $[M=48.1 \%]=$ eclectic $[M=48.4]$ reincarnationist $[M=38.3 \%]$ ), question type, $F(5,390)=189.93, p<.0001$ (psychobiological $[M=94.9 \%]=$ biological $[M=94.2 \%]>$ perceptual $[M=72.5 \%]>$ epistemic $[M=30.7 \%]=$ emotional $[M=30.1 \%]=$ 


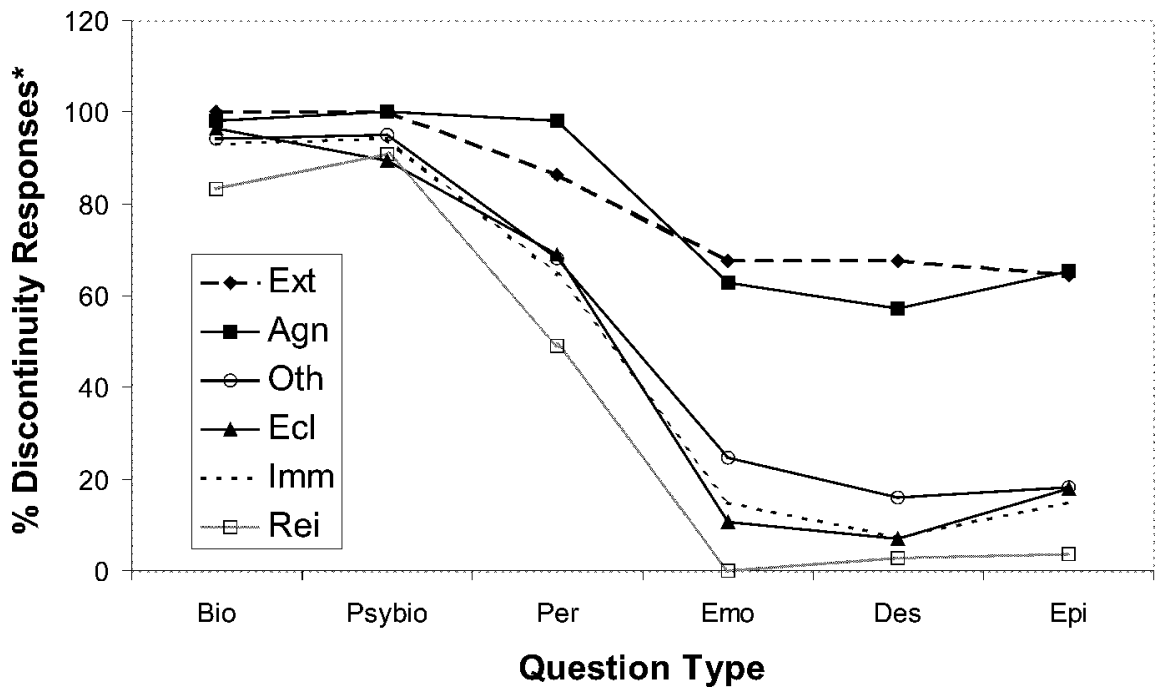

Figure 1. Percent of participants by afterlife believer-type reporting the different mental state types or biological imperatives would no longer function after the fictional character's (Richard Waverly or Tracey Davis) death. * Percentages reflect least squares means.

desire $[M=26.3 \%]$ ), and a significant question type $\times$ afterlife believertype interaction, $F(25,390)=4.46, p<.0001$.

Post-hoc analyses of the significant question type $\times$ afterlife believertype interaction using Tukey-Kramer test $(p<.05)$ revealed differences in the direction predicted by the simulation constraint model. As can be seen in Figure 1, all groups of participants stated that biological and psychobiological states ceased after death, and all showed a decrement in such responses for the emotional, desire, and epistemic categories. The major distinction lied between the extinctivists and agnostics at one extreme, and the remaining four groups at the other. Performance of the extinctivists and agnostics did not decline significantly for the perceptual questions and declined significantly less for the emotion, desire, and epistemic questions than for participants in the other four believe-type classifications. TukeyKramer tests did find a significant difference for responses to the different question types made for the extinctivists, where participants who classified themselves as such were significantly more likely to give discontinuity answers for the questions dealing with biological imperatives and psychobi- 
ological states than they were for those dealing with epistemic states (i.e., biological $=$ psychobiological $>$ epistemic). While their answers adhered to the predicted trend, all other question types were statistically treated the same by the extinctivists (i.e., biological $=$ psychobiological $=$ perceptual $=$ emotional $=$ desire). Participants who classified themselves as agnostics were at ceiling for the biological, psychobiological, and perceptual categories, each of which produced significantly more discontinuity responses than the epistemic, emotion, and desire categories (i.e., biological $=$ psychobiological $=$ perceptual $>$ epistemic $=$ emotion $=$ desire $)$. The same pattern was observed for participants classified as eclectics, although levels of discontinuity responses were significantly lower for the emotion, desire, and epistemic categories. Participants classified as immortalists and other believers similarly approached ceiling level performance for the biological and psychobiological questions, but showed a decline in discontinuity responses for perceptual questions, which in turn produced higher levels of discontinuity responses than the emotion, desire, and epistemic questions, which approached floor levels (i.e., biological $=$ psychobiological $>$ perceptual $>$ emotion $=$ desire $=$ epistemic). Finally, the reincarnationists, although following the same basic pattern as the immortalists and other believers, were significantly more likely to give discontinuity responses for questions dealing with psychobiological states than they were for those dealing with perceptual ones, while they were no more likely to provide discontinuity responses for the biological imperatives questions than they were for the perceptual questions (see Figure 1).

\section{Latencies to Provide Discontinuity Responses for Different Question Types}

Unfortunately, because both the question type and afterlife believer-type categories generated unequal numbers of discontinuity responses, such that some of the participants did not provide any discontinuity responses for certain question types (e.g., desire question type $\times$ immortalist afterlife believer-type), and others contributed disproportionately to such question types (e.g., desire question type $\times$ extinctivist afterlife believer-type), the latency data for discontinuity responses could not be statistically analyzed in an appropriate form using tests of significance. However, when looking at the overall trend of latencies to respond with a discontinuity answer for the different question types, treating each latency as an independent 


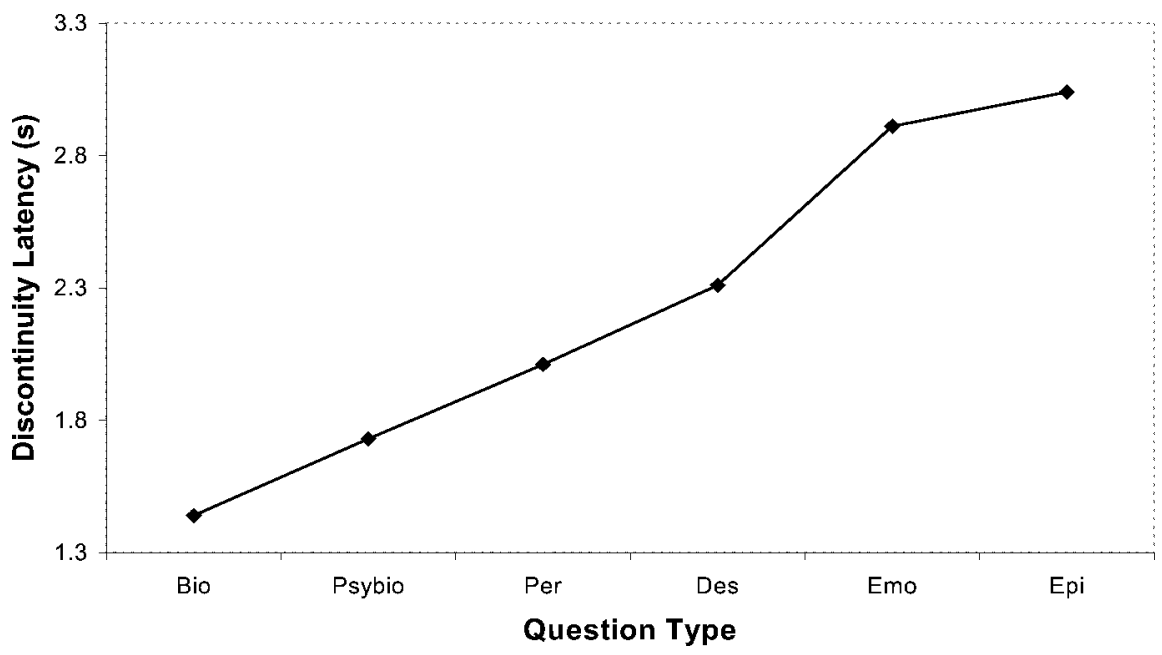

Figure 2. Average latency (in sec) of discontinuity responses by question type. Scores reflect latency between the end of the interview question and the participants' initial "no" response.

observation, the direction predicted by the simulationist model was clearly observed. In general, participants required more time to state that DIA states (emotional: $M=2.31 \mathrm{~s}$, quartile range $=.88-2.50 \mathrm{~s}$; desire: $M=2.91$ $\mathrm{s}$, quartile range $=1.25-3.88 \mathrm{~s}$, and; epistemic: $M=3.04 \mathrm{~s}$, quartile range $=1.22-3.72 \mathrm{~s}$ ) did not continue after death than they did for EIA states (psychobiological: $M=1.73 \mathrm{~s}$, quartile range $=.94-1.97 \mathrm{~s}$, and; and perceptual: $M=2.01 \mathrm{~s}$, quartile range $=.86-2.79 \mathrm{~s}$ ). In addition, discontinuity response latencies for the biological questions - the only question type that did not require the participants to reason about the mental abilities of the dead agent — were the shortest of all $(M=1.44$, quartile range $=.83-1.62 \mathrm{~s}$ ). For instance, to state that epistemic states ended at death took the participants on average over twice as long than to say the dead character was no longer subject to biological imperatives (see Figure 2).

\section{Discussion}

In general, the findings seem to fit the predictions made by simulation constraint theory. Individuals do, in fact, distinguish between the different types of mental states of spirits and ghosts as being more or less likely 
to follow them into the afterlife. The idea that consciousness poses an impediment to representing death as a state of nonbeing is not a new one (e.g., Hinde 1999; de Unamuno 1954). As the ethologist Hinde (1999, p. 60) speculated when reflecting on the cultural universality of afterlife beliefs, "It is difficult to imagine nonexistence, because one is imagining oneself as unable to imagine." However, the results reported in the current paper are the first empirical findings seeming to directly support this type of argument, showing, in general, that those states with which people conceptually should have the most difficulty imagining the complete absence of (i.e., epistemic, emotional, and desire states) are attributed to dead agents much more readily than are those states which are frequently absent from our everyday phenomenological reserve (i.e., psychobiological and perceptual states). The logic is simple. Because we know what it is like, for example, to have our vision occluded and subsequently not to be able to see anything, we are able to call upon those experiences of absence and more effectively represent the mental ability to see as ending at death than, say, the ability to think, which no sentient person has ever consciously been without. In terms of the cognitive underpinnings of religion, contrary to previous accounts (cf., Boyer, 2001), most afterlife believers do not represent ghosts and spirits simply as invisible human beings, but rather as invisible human beings with a narrower range of subjective experience than living agents - experience that is delimited by the inactivation of specific psychological systems at death.

\section{Representational Fixedness of Dead Agents'Minds: On Simulation and Theory Use}

Regardless of the explicit nature of one's beliefs about life after death, and irrespective of one's death-related anxiety, the findings show that, to the extent that a person expresses some belief in life after death, there is very little variability in the way the minds of dead agents are implicitly represented. That is, ghosts and spirits are more likely to be envisioned as possessing desire, emotional, and epistemic states than they are psychobiological and, in most cases, perceptual ones. This is the case whether one believes in the conventional Judeo-Christian conception of immortality, a literal reincarnation into another material animate form, some combination of both, or in some other, undefined existence of the self after death. To some extent, the data are surprising in that they seem 
to fit the simulationist hypotheses almost too well. For example, although they were the lowest of all, one would have expected the reincarnationists to have provided an even lower percentage of discontinuity responses for the biological and psychobiological questions than they did (83\% and $90 \%$, respectively), only if to support their stated explicit beliefs that "personal consciousness" becomes reincarnated into another physical body at some point after death. Likewise, given their adamancy on the questionnaires that personal consciousness is exhaustively terminated at death, it is somewhat surprising that the extinctivists were not at ceiling with discontinuity responses for the DIA mental states (i.e., emotional, desire, and epistemic states; 68\%, 68\% and 64\%, respectively), and in fact were significantly less likely to state that epistemic states discontinued after death than they were the two EIA states. Theoretically, if explicit (i.e., learned or adopted) beliefs were the whole story, reincarnationists should have been at absolute floor for all of the questions posed to them, and extinctivists at absolute ceiling.

In some sense, the findings reported here appear aligned with Barrett's (Barrett \& Keil 1996; Barrett 1998) discovery of a cognitive gap between "theologically correct" beliefs about supernatural agents and more conceptually primitive, automatic inferences used to reason about such agents' abilities in real time. Because explicit supernatural agent concepts can only survive by pirating automatic inference systems designed to reason about the minds of everyday intentional agents, they will necessarily be working against adaptive constraints that promote fast and ready representation of unobservable causal states. Just as parishioners reason that their omnipotent God must first finish answering one prayer before attending to the next (a constraint they would never place on God in an explicit task), the participants' explicit beliefs about life after death were not isomorphic with (and, in some cases, bore only a superficial resemblance to) their answers on the implicit interview task in the present study. However, here we have a case where supernatural agents (i.e., spirits) were not treated the same as regular human beings on an implicit task; rather, in many respects they were perceived as even more limited than regular human beings.

It is important to point out, perhaps, what the current findings do not mean. They do not mean that ghosts and spirits are always represented as deaf and blind, or that it is impossible to attribute to a dead agent 
such psychobiological states as thirst and hunger, or even, for that matter, as still requiring food and drink. There are countless examples in the anthropological literature of cultures that appear to treat the dead as if they were still living human beings, still subject to biological imperatives and with a healthy ensemble of mental states. When a death occurred among the ancient Hmong people of Asia, for example, elaborate funereal rituals included arranging a special meal for the deceased to prepare them for their long journey in the afterlife (Bliatout 1993). ${ }^{4}$ What the current findings do suggest is that such rituals are probably entirely symbolic in nature, and that followers do not actually believe, apart from the religioussymbolic context, that the dead still require food in any meaningful way. And, of course, because perceptual access is almost inseparable from epistemology, and because ghosts and spirits are so often envisioned as attuned to social goings-on (Boyer 2001; Hinde 1999; Reynolds \& Taylor 1995) and should therefore be dependent on their sensory faculties for acquiring knowledge of moral affairs, afterlife believers must find some way to attribute perceptual states to them. ${ }^{5}$ This may not be so easy to do, however. Take, for instance, one man's struggle to answer the question of whether the dead character would be able to smell the scent of cigarette smoke on the paramedic trying to resuscitate him: "This question is really confusing from my point of view or what I know. Again, the soul can smell and sense what we are doing, you know if we are smoking or not, but it is really not like the body does. In the soul it's a different way. I don't know how to explain it."

The findings simply show that certain types of mental states (i.e., DIA states) are more resistant to discontinuity reasoning and biological theorizing than are other types of mental states (i.e., EIA states), and therefore it is the

4"After the deceased has been bathed, dressed, and laid by the main pillar, a chicken egg and some rice are boiled and cooked. The food server to the dead is summoned and he offers the chicken egg and rice to the deceased" (Bliatout 1993, p. 89).

${ }^{5}$ It may be entirely unnecessary to attribute perceptual states to spirits, however. For instance, recent findings reported by Harris (2001) suggest that, as early as 5 years of age, children differentiate God's ways of knowing from those of everyday human beings. Children reasoned that while God's knowledge is not limited to information provided through the senses, human epistemology is always and necessarily grounded in perceptual access. Other supernatural agents' ways of knowing may be treated in the same manner as God's. 
former that will come to characterize the typical complexion of a ghost's mind on implicit tasks. This is not to say, however, that even on such tasks it is impossible to override these natural simulation constraints with explicit biological theorizing (in the case of extinctivists) or through the application of explicit religious concepts (in the case of reincarnationists). But, as the latency of discontinuity responses seem to show, reasoning that DIA states end at death requires more deliberate, conscious processing than reasoning that EIA states cease, because DIA states involves an alternative route to discontinuity reasoning than the natural default simulations employing the reserve phenomenology of absence or satiation.

That said, there may be other factors aside from simulation constraints that contributed to the pattern of findings reported here. For example, because mental states dealing with perception and psychobiology might be inherently linked to tacit knowledge of the physical body (e.g., Carey 1995; Coley 1995; Inagaki 1989; Johnson \& Wellman 1982; Slaughter et al. 1999), it may be no wonder that the participants viewed them as more likely subject to degradation than the more ephemeral aspects of consciousness, such as thoughts and emotions, that have no obvious connection to physicality aside from generating observable behavior. This would imply something like a marriage between folk psychology and folk biology, wherein the combination of the two domains gives birth to a set of naïve assumptions specific to the minds of dead agents. Such a naïve theory would hold that while ghosts are stripped of all ostensible biological (i.e., psychobiological) or physically entrenched (i.e., perceptual) mental states, they retain those mental states that have no direct observable connection to the external environment (i.e., emotional, desire, and epistemic). In this vein, it is the application of these synthetic naïve assumptions to the interview questions that culminated in the pattern of responses found in the current study, not simply the imposition of simulation constraints. In many cases, participants rejected the possibility that psychobiological and perceptual states continued by citing that these types of mental states were "physical things" or "functions of the body," whereas emotional, desire, and epistemic states went on because they were "spiritual things." However, because "theory-driven" accounts of other minds (e.g., Gopnik 1993; Gopnik \& Wellman 1992; Wellman \& Gellman 1998; Zaitchik 1990) are largely based on the logic that theories about mental states are 
refined and maintained with exposure to the observable behavior of natural agents, and are, in fact, completely dependent upon such observations, the mental states of ghosts and spirits pose special problems for such theory use because the behaviors of these agents do not take material form. Since any theory about the minds of dead agents cannot, therefore, be disconfirmed through direct observation of these agents' behavior, afterlife believers should be inclined to apply the same theory of mind when reasoning about ghosts as they do when reasoning about living people, and such a "ghost-specific" theory of mind should not easily come online.

Also, while a purely theory-driven theory might be generally convincing for the pattern of discontinuity responses, it is not as successful in accounting for the latency data, where the participants took, in general, longer to state that the more ephemeral aspects ceased at death. One of the defining features of naïve theory use, after all, is its automatic, rapid firing when target domains are triggered by their specialized input (Fodor 1983; Pinker 1997). Although there have been no empirical attempts, so far as I am aware, to determine whether this speed of processing is applied uniformly across native domains, there is no a priori reason to assume that certain facets of naïve theory will be deployed more swiftly than others. Ultimately it is likely not a black and white issue and will probably only be resolved by enlisting the more cogent explanatory appeals from both theory-driven and simulationist theoretical camps, as some scholars have already done with more traditional developmental problems of representational agency (e.g., Perner 1996; Tomasello 1999).

\section{"Born Believers" or Religious Concept Acquisition? What It Takes to Catch a Ghost}

The current findings join those of several studies (Barrett et al. 2001; Evans 2001; Giménez et al., unpublished manuscript) showing that religious concepts may not simply be enticing anomalies of intuitive concepts, or the mongrel progeny of cross-domain parenting, as held by many cultural epidemiologists (see Sperber \& Hirschfeld 1999), but rather have, in many cases, natural foundations in their own right. Should the simulationist model be borne out with additional empirical support, for example, the implication is that the social transmission process plays somewhat less a role in spreading ghost concepts than has been thought. Rather, implicit 
afterlife beliefs of the variety reported here would be characterized more or less as innate - piggybacking standard mental representational abilities specialized to human beings. Ghosts come from within, not without. Such a position would hold that the role of culture is in conceptually enriching (or degrading) such intuitive ghost concepts through explicit ideas, either capitalizing on their natural foundations (as in the conventional immortalist tradition) or by rebuking and overriding automatic inferences about the minds of dead agents (as in the extinctivist tradition). Of course, the standard lineup of core cognitive templates — along with their constraints - will be exploited by both everyday and religious concepts, but while cultural epidemiologists have a tendency to view these templates as a kind of "flypaper" which serves to capture the endogenous counterintuitive concepts generated by culture [e.g., ghost $=$ invisible + PERSON], the more nativistic position argues that implicit religious concepts, such as those dealing with afterlife beliefs and, perhaps, theism (Barrett et al. 2001; Bering 2001b, 2002a), are already in place and are only dependent upon such cultural input to flesh out intuitive forms. Although the acquisition of explicit concepts may indeed occur by way of ontological violations, this does not necessarily mean that they will not superimpose onto some implicit versions of these concepts that have their own unique evolutionary past.

The key point here lies in the discussion of native, implicit religious concepts. To the cultural epidemiologist, there are no such things. Religious concepts are acquired through cultural channels and are entirely explicit in nature; when you get right down to it, the story goes, they are not special in any sense. The rationale for this line of thinking is that religious concepts are socially acquired in the strictest sense and only function in real time by activating the mundane default inference systems placing constraints on them. This has been supported by previous work showing that people implicitly represent God as more "human" than not on implicit tasks (Barrett \& Keil 1996; Barrett 1998). The current findings raise important questions about this model, however, in that the mental abilities of spirits were not viewed in the same light as everyday human beings, but were instead subjected to special representational constraints specific to dead agents. Future research should lean toward investigating the intriguing possibility that humans are specially equipped to handle explicit 
religious input, not solely through parasitizing standard inferential systems, but also through the complex interaction of this input with what can only be described as intuitive religious concepts.

\section{REFERENGES}

Andresen, J.

2000 Religion in mind: Cognitive perspectives on religious belief, ritual, and experience. Cambridge: Cambridge University Press.

Anttonen, V. \& Pyysiäinen, I.

(in press) Cognition and religion: Cross-disciplinary perspectives. London: Continuum. ATRAN, S.

1989 Basic conceptual domains. Mind and Language 4, 7-16.

2002 In gods we trust: The evolutionary landscape of religion. Oxford University Press.

Atran, S. \& Norenzayan, A.

(in review) Religion's evolutionary landscape: Cognition, commitment, compassion. AVIS, J. \& HARRIS, P.L.

1991 Belief-desire reasoning among Baka children: Evidence for a universal conception of mind. Child Development 62, 460-467.

BAILLARGEON, R.

1993 The object concept revisited: New directions in the investigation of infants' physical knowledge. In C.E. Granrud (Ed.), Carnegie Symposium on Cognition: Visual Perception and Cognition in Infancy (pp. 265-315). Hillsdale, NJ: Erlbaum.

BARON-GOHEN, S.

1995 Mindblindness: An essay on autism and theory of mind. Cambridge, MA: MIT Press.

BARRETT, C.

1999 Human cognitive adaptations to predators and prey. Doctoral Dissertation, Dept. of Anthropology, University of California, Santa Barbara.

BARRETT, J.L.

1998a Cognitive constraints on Hindu concepts of the divine. Fournal for the Scientific Study of Religion 37, 608-619.

1998b Theological correctness: Cognitive constraint and the study of religion. Method \& Theory in the Study of Religion 11, 325-339.

2000 Exploring the natural foundations of religion. Trends in Cognitive Sciences 4, 29-34. BARRETT, J.L. \& KeIL, F.C.

1996 Anthropomorphism and God concepts: Conceptualizing a non-natural entity. Cognitive Psychology 31, 219-247.

BARRETT, J.L. \& Nyhof, M.A.

2001 Spreading non-natural concepts: The role of intuitive conceptual structures in memory and transmission of cultural materials. Fournal of Cognition and Culture 1, 69-100.

Barrett, J.L., Righert, R. \& Driesenga, A.

2001 God's beliefs versus mother's: The development of nonhuman agent concepts. Child Development 72, 50-65. 
BERING, J.M.

2001 a Theistic percepts in other species: Can chimpanzees represent the minds of non-natural agents? Journal of Cognition and Culture 1, 107-137.

$2001 \mathrm{~b}$ Are chimpanzees 'mere' existentialists? A phylogenetic approach to religious origins. Evolution and Cognition 7, 126-133.

2002a The existential theory of mind. Review of General Psychology 6, 3-24.

2002b 'Ratcheting' up the scalae naturae?' Review of The Cultural Origins of Human Cognition by M. Tomasello. Fournal of Cognition \& Culture 1, 353-358.

BERING, J.M. \& BJORKLUND, D.F.

March, 2002 The immortal mind: How human cognitive systems breed ghosts. Paper presented at the Cognition and Religion conference, Ann Arbor, MI.

Bering, J.M. \& Povinelli, D.J.

(in press) Comparing cognitive development: From bridging gaps to accepting diversity. In D. Maestripieri (Ed.), Primate psychology: Bridging the gap between the mind and behavior of human and nonhuman primates. Cambridge, MA: Harvard University Press.

BERMAN, A. \& HAYS, J.E.

1973 Relation between death anxiety, belief in afterlife, and locus of control. Fournal of Consulting and Clinical Psychology 41, 318-321.

Bjorklund, D.F. \& Pellegrini, A.D.

2002 The origins of human nature: Evolutionary developmental psychology. Washington, D.C.: American Psychological Association Press.

Bliatout, B.T.

1993 Hmong death customs: Traditional and acculturated. In D.P. Irish \& K.F. Lundquist (Eds.), Ethnic variations in dying, death, and grief: Diversity in universality. Series in death education, aging, and health care (pp. 79-100). Philadelphia, PA: Taylor \& Francis.

Boyer, P. \& RAMble, C.

2001 Cognitive templates for religious concepts: Cross-cultural evidence for recall of counter-intuitive representations. Cognitive Science 25, 535-564.

BOYER, P.

1994 The naturalness of religious ideas: A cognitive theory of religion. Berkeley: University of California Press.

1996 What makes anthropomorphism natural: Intuitive ontology and cultural representations. Fournal of the Royal Anthropological Institute 2, 83-97.

2000 Functional origins of religious concepts: Ontological and strategic selection in evolved minds. Fournal of the Royal Anthropological Institute 6, 195-214.

2001 Religion explained: The evolutionary origins of religious thought. New York: Basic Books.

Call, J. \& Tomasello, M.

1994 The production and comprehension of referential pointing by orangutans (Pongo pygmaeus). Fournal of Comparative Psychology 108, 307-317.

1999 A nonverbal theory of mind test. The performance of children and apes. Child Development 70, 381-395. 
CAREY, S.

1995 The growth of understandings of natural kinds. In D. Sperber, D. Premack \& A.J. Premack (Eds.), Causal cognition: A multi-disciplinary debate (pp. 268-302). Oxford: Clarendon Press.

Carey, S. \& Spelke, E.

1994 Domain-specific knowledge and conceptual change. In L. Hirschfeld \& S. Gelman (Eds.), Mapping the mind: Domain-specificity in cognition and culture (pp. 169200). New York: Cambridge University Press.

CAsebolt, J.

1992 The effect of terror management and the threatening or bolstering of afterlife beliefs on attributional derogation of AIDS victims. Unpublished raw data.

Chomsky, N.

1965 Aspects of the theory of syntax. Cambridge, MA: MIT Press.

Coley, J.D.

1995 Emerging differentiation of folkbiology and folkpsychology: Attributions of biological and psychological properties to living things. Child Development 66, 1856-1874.

EVANS, E.M.

2001 Cognitive and contextual factors in the emergence of diverse belief systems: Creation versus evolution. Cognitive Psychology 42, 217-266.

FLAVELL, J.H.

1999 Cognitive Development: Children's knowledge about the mind. Annual Review of Psychology 50, 21-45.

Flavell, J.H., Green, F.L. \& Flavell, E.R.

1995 Young children's knowledge about thinking. Monographs of the Society for Research in Child Development 60, 1.

Flavell, J.H. \& O’DOnNell, A.K.

1999 Development of intuitions about mental experiences. Enfance 3, 267-276.

FODOR, J.A.

1983 The Modularity of Mind. Cambridge, MA: MIT Press.

Gergely, G., Nádasdy, Z., Cisibra, G. \& Biró, S.

1995 Taking the intentional stance at 12 months of age. Cognition 56, 165-193.

Giménez, M., Guerrero, S. \& Harris, P.L.

(unpublished manuscript) Intimations of immortality and omniscience in early childhood.

GOLDman, A.I.

1993 The psychology of folk psychology. Behavioral and Brain Sciences 16, 15-28.

Gómez, J.-C.

1990 The emergence of intentional communication as a problem-solving strategy in the gorilla. In S.T. Parker \& K.R. Gibson (Eds.), "Language" and intelligence in monkeys and apes (pp. 333-355). Cambridge: Cambridge University Press. 
Gómez, J.-C. \& Teixidor, P.

1992 Theory of mind in an orangutan: A nonverbal test of false- belief appreciation. Paper presented at the XIV Congress of the International Primatological Society, Strasbourg.

GOODALL, J.

1990 Through a window. Boston: Houghton Mifflin.

GOPNIK, A.

1993 How we know our minds: The illusion of first-person knowledge of intentionality. Behavioral and Brain Sciences 16, 1-14.

Gopnik, A. \& Wellman, H.M.

1992 Why the child's theory of mind really is a theory. Mind \& Language 7, 145-171.

GuTHRIE, S.

1993 Faces in the clouds. New York: Oxford University Press.

Greeley, A.M. \& Hout, M.

1999 Americans' increasing belief in life after death: Religious competition and acculturation. American Sociological Review 64, 813-835.

Hare, B., Call, J., Agnetta, B. \& Tomasello, M.

2000 Chimpanzees know what conspecifics do and do not see. Animal Behaviour 59, 771-785.

Hare, B., Call, J. \& Tomasello, M.

2001 Do chimpanzees know what conspecifics know? Animal Behaviour 61, 139-151.

HARPER, P.

1996 Two death experiences in the life of Adelaide Zoo's chimpanzee group. Australian Primatology 10, 11-14.

HARRIS, P.L.

1991 The work of the imagination. In A. Whiten (Ed.), Natural theories of mind: Evolution, development and simulation of everyday mindreading.

1992 From simulation to folk psychology: The case for development. Mind and Language 7, 120-44.

2001 Thinking about the unknown. Trends in Cognitive Sciences 5, 494-498.

Heyes, C.

1998 Theory of mind in nonhuman primates. Behavioral and Brain Sciences 21, 101-134.

HiLl, P.C. \& HOOD, R.W.

1999 Measures of religiosity. Birmingham, AL: Religious Education Press.

HINDE, R.A.

1999 Why gods persist: A scientific approach to religion. London: Routledge.

INAGAKI, K.

1989 Developmental shift in biological inference processes: From similarity-based to category-based attribution. Human Development 32, 79-87.

Johnson, C.N. \& Wellman, H.M.

1982 Children's developing conceptions of the mind and brain. Child Development 53, $222-234$ 
KARIN-D'ARGy, M.R. \& Povinelli, D.J.

(in review) Do chimpanzees know what each other see? A closer look.

KARMiLOFF-Smith, A.

1992 Beyond modularity: A developmental perspective on cognitive science. Cambridge, MA: MIT Press.

KITA, S.

(in press) Pointing: Where language, culture, and cognition meet. Hillsdale, NJ: Erlbaum.

KURLYCHEK, R.T.

1976 Level of belief in afterlife and four categories of fear of death in a sample of 60+-year-olds. Psychological Reports 38, 228.

Lawson, E.T. \& MCGauley, R.N.

1990 Rethinking religion: Connecting cognition and culture. Cambridge: Cambridge University Press.

Littlefield, C. \& Fleming, S.

1984 Measuring fear of death: A multidimensional approach. Omega: Fournal of Death E Dying 15, 131-138.

Lonetto, R. \& Templer, D.I.

1986 Death anxiety. New York: Hemisphere.

Malley, B.E.

1996 The emerging cognitive psychology of religion: A review article. Method \& Theory in the Study of Religion 8, 109-141.

Matsuzawa, T.

1997 The death of an infant chimpanzee at Bossou, Guinea. Pan Africa Neres 4, 4-6.

OrsarchuK, M. \& TATZ, S.J.

1973 Effect of induced fear of death on belief in afterlife. Fournal of Personality \& Social Psychology 27, 256-260.

PERNER, J.

1996 Simulation as explicitation of predication-implicit knowledge about the mind: Arguments for a simulation-theory mix. In P. Carruthers \& P.K. Smith (Eds.), Theories of theories of mind (pp. 90-104). Cambridge: Cambridge University Press.

PINKER, S.

1997 How the minds works. New York: Norton.

Povinelli, D.J.

2000 Folk physics for apes: The chimpanzee's theory of how the world works. Oxford: Oxford University Press.

Povinelli, D.J., Bering, J. \& Giambrone, S.

2000 Toward a science of other minds: Escaping the argument by analogy. Cognitive Science 24, 509-541.

Povinelli, D.J., Bierschwale, D.T. \& Čech, G.G.

1999 Comprehension of seeing as a referential act in young children, but not juvenile chimpanzees. British Fournal of Developmental Psychology 17, 37-60. 
Povinelli, D.J. \& EDdy, T.J.

1996 What young chimpanzees know about seeing. Monographs of the Society for Research in Child Development 61, 3.

Povinelli, D.J., Nelson, K.E. \& Boysen, S.T.

1990 Inferences about guessing and knowing by chimpanzees (Pan troglodytes). Fournal of Comparative Psychology 104, 203-210.

1992 Comprehension of role reversal by chimpanzees: Evidence of empathy? Animal Behaviour 43, 633-640.

Povinelli, D.J. \& O’Neill, D.K.

2000 Do chimpanzees use their gestures to instruct each other in cooperative situations? In S. Baron-Cohen, H. Tager-Flusberg \& D.J. Cohen (Eds.), Understanding other minds: Perspectives from developmental cognitive neuroscience (pp. 459-487). Oxford: Oxford University Press.

Premack, D. \& WoOdRufF, G.

1978 Does the chimpanzee have a theory of mind? Behavioral and Brain Sciences 1, 515-526.

Reaux, J.E., Theall, L.A. \& Povinelli, D.J.

1999 A longitudinal investigation of chimpanzees' understanding of visual perception. Child Development 70, 275-290.

REYNOLDS, V. \& TAYLOR, R.

1995 The social ecology of religion. New York: Oxford University Press.

Rosengren, K.S., Johnson, C.N. \& Harris, P.L.

2000 Imagining the impossible: Magical, scientific, and religious thinking in children. Cambridge: Cambridge University Press.

SCHOENRADE, P.

1987 When I die... : Belief in afterlife as a response to mortality. Personality E् Social Psychology Bulletin 15, 91-100.

Slaughter, V. JAAK Ola, K. \& Carey, S.

1999 Constructing a coherent theory: Children's biological understanding of life and death. In M. Siegal \& C. Peterson (Eds.), Children's understanding of biology, health, and ethics (pp. 71-96). Cambridge: Cambridge University Press.

Smith, P.C., Range, L.M. \& Ulmer, A.

1992 Belief in afterlife as a buffer in suicidal and other bereavement. Omega: Fournal of Death \& Dying 24, 217-225.

SPELKE, L.S.

1991 Physical knowledge in infancy: Reflections on Piaget's theory. In S. Carey \& R. Gelman (Eds.), The Epigenesis of Mind: Essays on Biology and Cognition (pp. 133-169). Hillsdale, NJ: Erlbaum.

SPELKE, E.S.

1994 Initial knowledge: Six suggestions. Cognition 50, 431-445. 
SPERBER, D.

1994 The modularity of thought and the epidemiology of representations. In L. Hirschfeld \& S. Gelman (Eds.), Mapping the Mind: Domain specificity in cognition and culture, (pp. 39-62). New York: Cambridge University Press.

SPERBER, D. \& Hirschfeld, L.

1999 Culture, cognition, and evolution. In Wison, R.A. \& Keil, F.C. (Eds.), The MIT encyclopedia of the cognitive sciences (pp. cxi-cxxxii). Cambridge, MA: MIT Press.

Sperber, D., Premack, D. \& Premack, A.J.

1995 Causal cognition: A multidisciplinary debate. New York: Oxford University Press.

Suddendorf, T. \& Whiten, A.

2001 Mental evolution and development: Evidence for secondary representation in children, great apes and other animals. Psychological Bulletin 127, 629-650.

TELEKI, G.

1973 Group responses to the accidental death of a chimpanzee in Gombe National Park, Tanzania. Folia Primatologica 20, 81-94.

Thalbourne, M.A.

1996a Varieties of belief in life after death: A factor-analytic approach. Fournal of the American Society for Psychical Research 90, 268-291.

1996b Belief in life after death: Psychological origins and influences. Personality and Individual Differences 21, 1043-1045.

TEMPLER, D.I.

1970 The construction and validation of a death anxiety scale. Fournal of General Psychology 82, 165-177.

TEMPleR, D.I. \& RuFF, G.F.

1975 The relationship between death anxiety and religion in psychiatric patients. Fournal of Thanatology 3, 165-168.

Tomasello, M.

1996 Do apes ape? In B.G. Galef, Jr. \& C.M. Heyes (Eds.), Social learning in animals:

The roots of culture (pp. 319-346). New York: Academic Press.

1999 The cultural origins of human cognition. Boston: Harvard University Press.

Tomasello, M. \& Call, J.

1997 Primate cognition. New York: Oxford University Press.

Tomasello, M., Call, J. \& Gluckman, A.

1997 The comprehension of novel communicative signs by apes and human children.

Child Development 68, 1067-1081.

Tomasello, M., Kruger, A. \& Ratner, H.

1993 Cultural learning. Behavioral and Brain Sciences 16, 495-511.

DE Unamuno, M.

1954/1913 Tragic sense of life. New York: Dover.

DE WAAL, F.

1996 Peacemaking among primates. Cambridge, MA: Harvard University Press. 
Wellman, H.M., Cross, D. \& Watson, J.

2001 Meta-analysis of theory-of-mind development: The truth about false belief. Child Development 72, 655-684.

Wellman, H.M. \& Gelman, S.A.

1998 Knowledge acquisition in foundational domains. In D. Kuhn \& R.S. Siegler (Eds.), Handbook of child psychology. Vol. 2 (pp. 523-573). New York: John Wiley.

White, W. \& HANDAL, P.J.

1991 The relationship between death anxiety and mental health/distress. Omega: Fournal of Death \& Dying 22, 13-24.

Whitehouse, H.

1995 Inside the cult: Religious innovation and transmission in Papua New Guinea. Oxford: Clarendon Press.

2001 Transmissive frequency, ritual, and exegesis. Fournal of Cognition \& Culture 1, 167-181.

WOOLley, J.D.

2001 The development of beliefs about mental-physical causality in imagination, magic, and religion. In K.S. Rosengren, C.N. Johnson \& P.L. Harris (Eds.), Imagining the impossible: The development of magical, scientific, and religious thinking in children. Cambridge: Cambridge University Press.

Woolley, J.D. \& Phelps, K.

2001 The development of children's beliefs about prayer. Fournal of Cognition \& Culture 1, 139-166.

ZAITGHIK, D.

1990 When representations conflict with reality: The preschooler's problem with false beliefs and "false" photographs. Cognition 35, 41-68.

ZELLER, A.

1991 The grieving process in non-human primates. In D.R. Counts \& D.A. Counts (Eds.), Coping with the final tragedy: Cultural variation in dying and grieving (pp. 5-26). Amityville, NY: Baywood.

\section{Appendix 1. Afterlife vignettes and interview questions}

\section{Script A. Richard Waverly}

This morning, Richard Waverly, a 37-year-old history teacher, scrambled to get to work on time. He was running late, and so he didn't have time to eat breakfast, even though he was extremely hungry. It wasn't starting off to be a very good day. Richard felt a little sick and thought he might be coming down with something because he awoke with a sore throat. He was very thirsty and he thought that some cold orange juice might make him feel better, but he didn't even have enough time to pour himself a glass of juice. There really was no time at all to spare, so he quickly got into his car and headed for the school. 
While driving, he realized how tired he was; he almost fell asleep at the wheel several times! He didn't get much sleep the night before. He was going to teach his students about the American Constitution today, and so last night he had stayed up late in order to read up on the history of the Constitution and its various Amendments. Fortunately, he was now confident that he knew the information well and could answer any questions that the students might have. But he also wanted to teach his students the names of all the U.S. vice presidents after 1800; unfortunately, he didn't have time to study them, and he hardly knew any of their names!

In general, Richard was also in a bit of a bad mood today. He was angry at his wife, Martha, because she did not get home until midnight last night, and she had refused to tell him where she had been. They had both gone to bed moody. Richard suspected that Martha was having an affair, but he hadn't the courage to confront her about it, and he didn't have any real evidence that she was. $\mathrm{He}$ really did love his wife, and so the idea of her being with another man upset him greatly. He didn't want to think about it.

Richard popped a strong breath mint in his mouth and chewed it rapidly. As he neared the intersection before the school, he leaned over to close the passenger window - he thought this might save him some time since he wouldn't have to do it after he parked. Unfortunately, while leaning over, his foot accidentally slipped off the break and onto the accelerator, and his car went head first into a utility pole. He wasn't wearing his seat belt and he was ejected from the car, landing on the pavement. A frantic witness called the paramedics immediately, but when they arrived on the scene Richard Waverly was already dead. They were certain that he died instantaneously.

\section{Script A. Interview Questions}

\section{Biological}

1. Do you think that Richard will ever need to eat food again?*

2. Do you think that Richard will ever need to drink water again?

3. Do you think that Richard will ever need to go to the bathroom again?

4. Do you think that Richard's brain still works?

\section{Psychobiological}

1. Do you think that Richard is still hungry?

2. Do you think that Richard is still thirsty?

3. Do you think that Richard still feels sick?

4. Do you think that Richard can ever be sexually aroused again? 


\section{Perceptual}

1. Do you think that Richard can hear the paramedics talking?

2. Do you think that Richard can see the paramedics trying to resuscitate him?

3. Do you think that Richard can still taste the flavor of the breath mint?

4. One of the paramedics is a very heavy smoker; do you think that Richard can smell the scent of cigarette smell on him?

\section{Emotional}

1. Do you think that Richard is still angry at his wife Martha?

2. Do you think that Richard still loves his wife?

3. Do you think that Richard is now happy?

4. Do you think that Richard is still hurt at Martha's behavior last night?

\section{Desire}

1. Do you think that Richard wants to be alive?

2. Do you think that Richard wishes he told his wife he loved her before he died?

3. Do you think that Richard longs to see his wife?

4. Do you think that Richard desires that his wife be happy?

\section{Epistemic}

1. Do you think that Richard believes that his wife loved him?

2. Do you think that Richard is still thinking about his wife Martha?

3. Do you think that Richard knows that he's dead?

4. Do you think that Richard still remembers everything he learned last night about the American Constitution?

* Each question was prefaced with the conditional, "Now that Richard is dead..."

\section{Script B. Tracey Davis}

This morning, Tracey Davis woke up with a very bad headache. The previous night she had gotten into a very loud argument with her daughter, Rachel, because she suspected that Rachel had stolen money from her purse in order to buy drugs. Tracey looked at her alarm clock and realized that she was running late for work. She showered quickly, but did not have time to drink or eat anything before she left, although she was incredibly hungry and her throat was dry from yelling and made her very thirsty. She went quickly to the train station and headed for the office.

While she was sitting on the train, she realized how tired she was. She had been thinking all night about her daughter and the possibility that she was taking 
drugs, even though her daughter had absolutely denied it. She was so worried that she had not slept a wink all night. Then she remembered that she was supposed to have prepared a briefing for the president of her firm the night before. Although she had spent the day yesterday reading about the current employment rates for the company, and felt she could answer any questions about employment that the president might have, she was also supposed to have been able to report to him today about the current financial status of the company. But she had been so caught up with Rachel that she did not have time to prepare this information and had no idea what the current financial status of the company actually was.

Overall, Tracey Davis was in a very bad mood today. Even though she loved her daughter Rachel very much, she was also very angry with her. To be honest, she had no evidence that her daughter had actually been using drugs, but she had still been very distant from her lately. She vowed that she would get to the bottom of the matter as soon as she got home from work today.

Tracey found a bottle of aspirin in her purse and swallowed two pills for her headache, which had grown worse. The taste of the aspirin was very strong and chalky, and almost made her gag. Just then, a terrible crushing sound came from the front of the train and people were tossed everywhere. The train had come dislodged from its tracks and rolled down a steep embankment. Tracey died instantaneously when a large piece of metal struck her on the head.

\section{Script B. Interview Questions}

\section{Biological}

1. Do you think that Tracey will ever need to eat food again?*

2. Do you think that Tracey will ever need to drink water again?

3. Do you think that Tracey will ever need to go to the bathroom again?

4. Do you think that Tracey's brain still works?

\section{Psychobiological}

1. Do you think that Tracey is still hungry?

2. Do you think that Tracey is still thirsty?

3. Do you think that Tracey still feels sick?

4. Do you think that Tracey can ever be sexually aroused again?

\section{Perceptual}

1. Do you think that Tracey can hear the survivors and paramedics talking?

2. Do you think that Tracey can see the survivors of the wreck scrambling around her?

3. Do you think that Tracey can still taste the flavor of the aspirin? 
4. One of the paramedics is a very heavy smoker; do you think that Tracey can smell the scent of cigarette smell on him?

\section{Emotional}

1. Do you think that Tracey is still angry at her daughter Rachel?

2. Do you think that Tracey still loves her daughter?

3. Do you think that Tracey is now happy?

4. Do you think that Tracey is still hurt that Rachel has been distant from her lately?

Desire

1. Do you think that Tracey wants to be alive?

2. Do you think that Tracey wishes she told her daughter she loved her before she died?

3. Do you think that Tracey longs to see her daughter?

4. Do you think that Tracey desires that her daughter be happy?

\section{Epistemic}

1. Do you think that Tracey believes that her daughter loved her?

2. Do you think that Tracey is still thinking about her daughter Rachel?

3. Do you think that Tracey knows that she's dead?

4. Do you think that Tracey still remembers everything she learned last night about the employment rate for her company?

* Each question was prefaced with the conditional, "Now that Tracey is dead..."

\section{Appendix 2. Combined Belief in Afterlife (BA) Scale (after Orsarchuk \& Tatz 1973) and Death Anxiety Scale (ANX[d]) (after Templer 1970)}

1. It doesn't make me nervous when people talk about death. (ANX[d])

2. Earthly existence is the only existence we have. (BA)

3. I dread to think about having to have an operation. (ANX[d])

4. In the premature death of someone close, some comfort can be found in knowing that in some way the deceased is still existing. (BA)

5. I am not at all afraid to die. (ANX[d])

6. Humans die in the sense of "ceasing to exist." (BA)

7. I am not particularly afraid of getting cancer. (ANX[d])

8. There must be an afterlife of some sort. (BA)

9. The thought of death never bothers me. (ANX[d])

10. We will never be united with those deceased whom we knew and loved. (BA)

11. I am often distressed by the way time flies so very rapidly. (ANX[d]) 
12. Some existentialists claim that when people die they ceases to exist: I agree. (BA)

13. I fear dying a painful death. (ANX[d])

14. The following statement is true: "There is no such thing as life after death." (BA)

15. The subject of life and death troubles me greatly. (ANX[d])

16. Millions of people believe in a life after death: they are correct in so believing. (BA)

17. Enjoy yourself on earth, for death signals the end of all existence. (BA)

18. I am really scared of having a heart attack. (ANX[d])

19. A belief in an afterlife may be useful for some, but I don't believe in it at all. (BA)

20. I often think about how short life really is. (ANX[d])

21. The life we lead now is but a pebble cast upon the sands of our future lives. (BA)

22. I shudder when I hear people talking about a World War III. (ANX[d])

23. Religiously associated or not, belief in an afterlife will never be shown to be true, for afterlives are nonexistent. (BA)

24. The sight of a dead body is horrifying to me. (ANX[d])

25. The following statement is true: "Humans must enter into some sort of existence after death, for the end of our earthly lives cannot wipe us from existence into nothingness." (BA)

26. I feel that the future holds nothing for me to fear. (ANX[d])

27. When a human dies, that something called "life" dies with him or her. (BA)

28. I am very much afraid to die. (ANX[d])

29. The idea of there existing somewhere some sort of afterlife is beyond my comprehension. (BA)

30. The thought of death seldom enters my mind. (ANX[d])

31. The millions killed by Hitler passed from existence into nothingness. (BA)

32. Many scientists believe in a life after death: they are right, there is one. (BA)

33. There is supportive evidence for the existence of an afterlife. (BA)

34. Death ends all forms of life forever. (BA)

35. The existence of an afterlife can never be scientifically demonstrated, for it is impossible to prove a "figment of someone's imagination." (BA) 


\section{Appendix 3. Afterlife Believer-type Self Glassifications (after Thalbourne 1996b, p. 1045)}

Instructions: Read each of the following sentences carefully and choose the one that best describes your beliefs about life after death

[ ] What we think of as the "soul", or conscious personality of a person, ceases permanently when the body dies. [extinctivist*]

[ ] After death, the "conscious personality" continues for a while on a different plane and then is reincarnated into a new body on Earth or elsewhere; this reincarnation process occurs over and over again, and may culminate in the individual being absorbed into a Universal Consciousness. [reincarnationist]

[ ] The "conscious personality" survives the death of the body; it does not reincarnate into another body, but continues to exist forever; there may (or may not) be a day when the dead rise again from the grave. [immortalist]

[ ] The "conscious personality" survives the death of the body, and indeed is immortal; it may be reincarnated into a new body, this process occurring over and over again; there may (or may not) be a "Resurrection of the Dead". [eclectic] [] The "conscious personality" survives the death of the body, but I am completely unsure as to what happens to it after that. [other believer]

[] I am completely uncertain as to what happens to the "conscious personality" at the death of the physical body. [agnostic]

* The names shown in square brackets are for descriptive purposes only and were not included in the original questionnaire.

\section{Appendix 4. Goding Guidelines for Interview Sessions}

Griteria establishing continuity reasoning (the specific mental state or biological imperative is envisioned to continue functioning despite the character's death), discontinuity reasoning (the specific mental state or biological imperative is envisioned to have ceased functioning as a result of the character's death), are reported below, along with examples of actual responses.

Continuity - Participant responds "yes" to initial target question and does not contradict this answer in his or her response to the follow-up question(s) (see Example 1a). If participant does not provide descriptive answer at follow-up questioning for initial "yes" response (e.g., shrugs shoulder, states "I don't know", etc.), then a continuity score is recorded (see Example 1b). Also, a continuity score is recorded when participant responds "no" to initial target question, but his or her answer to subsequent follow-up questioning indicates continuity reasoning (see Example 1c). 


\section{Example 1a}

E: Do you think that Richard wishes he told his wife he loved her before he died?

P: Yes.

E: How come?

P: Because he didn't want it to end the way it did.

\section{Example 1b}

E: Do you think that Richard is still thinking about his wife Martha?

P: Yes.

E: Why?

P: I don't know.

\section{Example 1c}

E: Do you think that Tracey is still hurt that Rachel has been distant from her lately?

P: No.

E: Why not?

P: Because she's probably able to understand now how Rachel was really feeling.

Discontinuity - Participant responds "no" to initial target question and provides a justification for this response indicating cessation of function for particular faculty during follow-up questioning (see Examples $2 \mathrm{a}$ and $2 \mathrm{~b}$ below).

\section{Example 2a}

E: Do you think that Tracey can see the survivors of the wreck scrambling around her?

P: I would say no.

E: Why would you say that?

P: Because as soon as you die I think that you go straight into another world.

E: Ok, what do you mean by that? Elaborate on it.

P: No, because when she dies she doesn't have a brain anymore because she's unconscious. Nobody that's unconscious can see anybody.

\section{Example 2b}

E: Do you think that Richard believes that his wife loved him?

P: No. He couldn't believe anything after death because that would involve mental activity. 
Copyright of Journal of Cognition \& Culture is the property of Brill Academic Publishers and its content may not be copied or emailed to multiple sites or posted to a listserv without the copyright holder's express written permission. However, users may print, download, or email articles for individual use. 